\title{
ENHANCED RECOVERY AFTER SURGERY (ERAS) COLORECTAL PROGRAMME
}

\section{IN A TERTIARY HOSPITAL: BETTER COMPLIANCE, BETTER RESULTS?}

\author{
Alonso Aguilar L., Barbero Mielgo M., San Román San Antonio B., Molnar V. \\ ${ }^{1}$ Hospital Puerta de Hierro Majadahonda
}

\section{BACKGROUND AND GOAL OF STUDY:}

ERAS protocol in colorectal surgery (CRS) reduces length of hospital stay(LOS) and complication rate.

Despite of the evidence their full implementation into daily practice meets certain difficulties.

We review how adherence to the protocol (compliance) determines results in the implementation of the ERAS protocol in a tertiary hospital.

\section{MATERIALS AND METHODS:}

We examine a prospective cohort of patients operated on colorectal surgery (CRS) under ERAS program based on international guidelines: 165patients (101men/64women) (surgery: 57open, 108laparoscopic) between January and November 2017. Average age was 67.54ys (SD=12.34).

We evaluate if increasing compliance $(<70 \%,>70 \%,>80 \%,>90 \%, 100 \%)$ have any repercussion in complications (defined using the Clavien-Dindo classification), readmission rate and LOS (aiming for discharge on day 5 ).

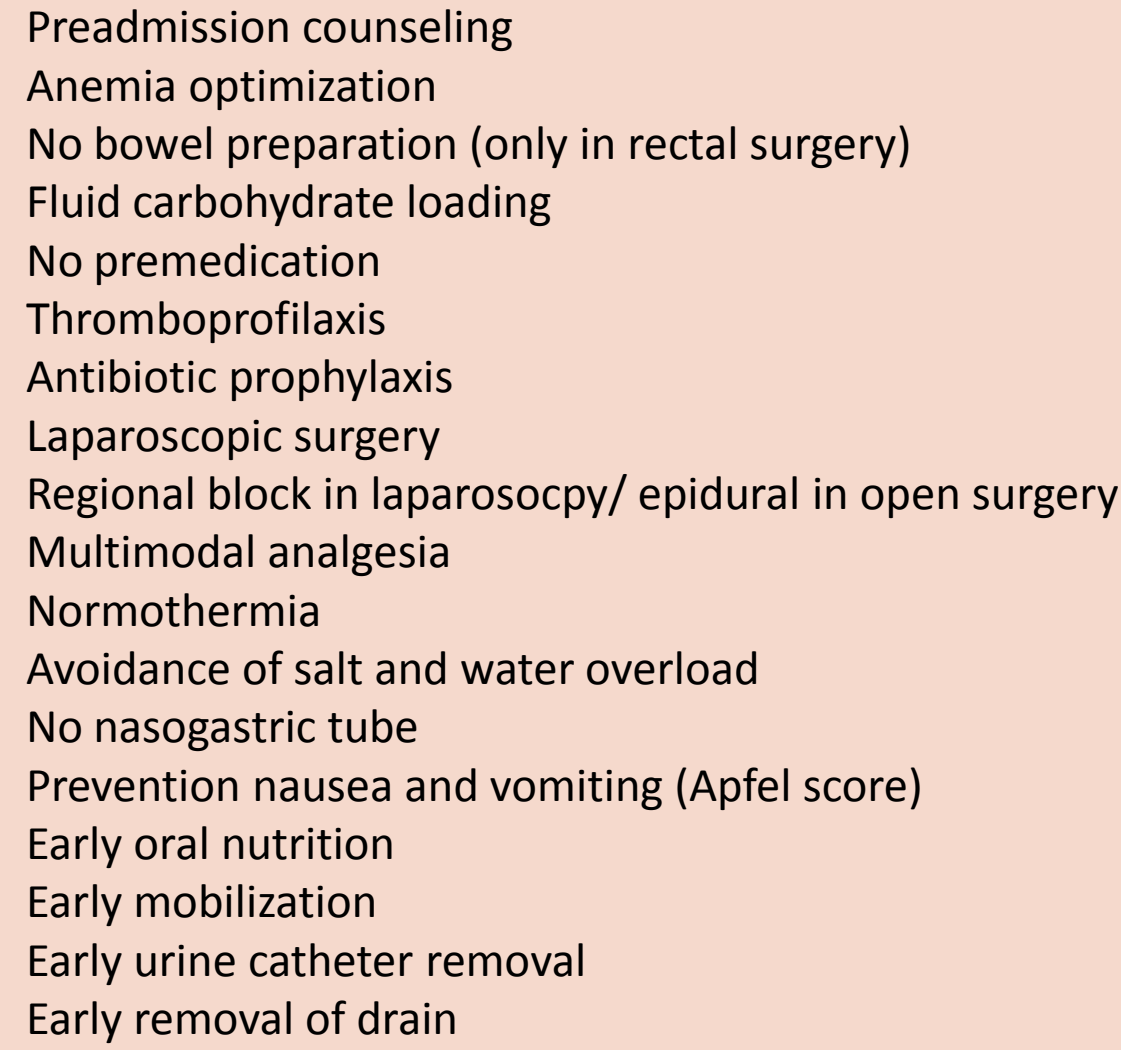

\section{DISCHARGE CRITERIA}

Solid oral tolerance

Pain control with oral analgesics

Deambulation

Gas/stool output

No nausea

Correct stoma self-care with controlled output

No postoperative complications

- $\quad P C R<50$

- Wanted discharge

RESULTS AND DISCUSSION:

\begin{tabular}{|c|c|c|c|c|c|c|c|c|c|c|}
\hline $\begin{array}{l}\text { Compliance } \\
(\%)\end{array}$ & $\begin{array}{l}\text { Laparoscopic } \\
\text { surgery (\%) }\end{array}$ & $\begin{array}{c}\text { Rectal } \\
\text { Surgery (\%) }\end{array}$ & $\begin{array}{l}\text { CD I } \\
(\%)\end{array}$ & $\begin{array}{l}\text { CD II } \\
(\%)\end{array}$ & $\begin{array}{l}\text { CD III } \\
(\%)\end{array}$ & $\begin{array}{l}\text { CD IV } \\
(\%)\end{array}$ & $\begin{array}{l}\text { CD V } \\
(\%)\end{array}$ & $\begin{array}{l}\text { Readmission } \\
\text { (\%) }\end{array}$ & $\begin{array}{l}\text { Discharge on } \\
\text { day } 5 \text { PO (\%) }\end{array}$ & $\begin{array}{c}\text { LOS (days) } \\
\text { P50 [p25-p75] }\end{array}$ \\
\hline $\begin{array}{l}<70 \\
(n=12)\end{array}$ & 58,3 & 41,7 & 58,3 & 33,3 & 0 & 0 & 0 & 0 & 16,7 & 6 [9-13] \\
\hline $\begin{array}{l}70-79 \\
(n=25)\end{array}$ & 60 & 36,0 & 68,0 & 16,7 & 12,0 & 4 & 0 & 4 & 12 & $8[6-13]$ \\
\hline $\begin{array}{l}80-89 \\
(n=62)\end{array}$ & 64,5 & 29,0 & 45,2 & 16,1 & 8,1 & 3,2 & 0,01 & 1,6 & 30,6 & $6[5-9,5]$ \\
\hline $\begin{array}{l}90-99 \\
(n=46)\end{array}$ & 73,9 & 28,3 & 37,0 & 17,8 & 4,3 & 4,3 & 0 & 2,2 & 41,3 & 6 [5-9] \\
\hline $\begin{array}{c}100 \\
(n=12)\end{array}$ & 83,3 & 16,7 & 25 & 0 & 0 & 0 & 0 & 0 & 58,3 & $5[5-6]$ \\
\hline$P$ value & 0,058 & $>0,1$ & $0,003^{*}$ & $>0,1$ & $>0,1$ & $>0,1$ & $>0,1$ & $>0,1$ & $0,01^{*}$ & $0,009^{*}$ \\
\hline
\end{tabular}

\section{CONCLUSIONS:}

When compliance increases, there is a trend in reducing complications (grade I,II,II) and LOS with more patients being discharge at day 5 .

We should make bigger groups to observe stadistically significative differences. 